\title{
Preliminary Study on Experimental Curriculum Reform of Real Estate Sand Table
}

\author{
Wanli Wang ${ }^{1, a}$, Ming Hong ${ }^{1, b}$
}

\author{
2800 Wenxiang Road, Shanghai Lixin University of Accounting and Finance, Shanghai, \\ China \\ agwwanli@163.com, bhongming556@126.com
}

Keywords: Real Estate; Sand Table; Occupation Orientation.

\begin{abstract}
Based on the practice of the curriculum reform of the real estate sand table experiment, this paper analyzes the problems of the students' lack of attention in the class, and finds that the fault of the selection of the experimental roles is the crux of the problem. So, the curriculum reform introduced the professional personality in the selection of the manager roles. Through the actual observation, it is found that the students' interest in the curriculum is greatly strengthened after the curriculum reform, and the questionnaire and individual interview also show that the curriculum reform which is combined with psychology, not only has some effect on the experimental teaching, but also has considerable significance for the of students' employment.
\end{abstract}

\section{Introduction}

Experimental Curriculum of Real Estate Sand Table(ECREST) is one of the compulsory courses to real estate majors of our university. It not only runs through the related contents of real estate technology, management, economy, law and other related courses, but also involves many fields of knowledge in the real estate industry. It helps students to establish a comprehensive ability to consider the whole process of development, operate and management. It truly assists students to understand the impact of planning, design, development cycle, financing cost, marketing strategy and other aspects on the profitability, growth, stability, and liquidity of the enterprise. It is a bridge linking students' basic knowledge and professional knowledge with future career planning and occupation orientation.

This course allows students to manage a company in a virtual and complex environment to simulate the entire development cycle of real estate projects from macro-environment analysis, market survey, land bidding, project positioning, investment and financing plan, design planning, construction to market sales. In the course each development company consists of 5-7 students, which are CEO, design director, engineering director, sales director, cost director and finance director. Students should face the dynamic market according to supply and demand situation, use visual sand teaching tools, simulate the full cycle development and operation of real estate projects for four years in a week, and experience the responsibilities, tasks and functions of different professional roles in the real estate economy.

This course has been widely recognized by students since it was opened in our university in 2010. In the course of the seven round of teaching in 2010 - 2016, we find that the existing problems are mainly shown in three aspects. 
The first problem is that students are not well aroused the leaning enthusiasm. We found that some students with better results in the course were busy calculating; the rest of the students had nothing to do, even skipping classes. The emergence of this phenomenon is mainly due to students' lack of psychological preparation for the transformation of social roles. The social role of professionals is mainly based on knowledge application, which is a process of performing duties and taking risks to serve the society and not just learning knowledge.

The second problem is that students misunderstand the rules of professional roles in the virtual company. Obviously the role of CEO, design director, engineering director, sales director, cost director and chief financial officer has different professional positions, responsibilities and rights. In the past courses some students can not actively participate in the simulation operation of real estate enterprise because of misunderstanding of those roles, and cannot be trained effectively for a long time. In the other hand, few students who can master the rules almost do all the work. Because their responsibilities are too complex and confused, they cannot deeply think about the rights and obligations of the job and cannot also deal with all kinds of problems in the operation flexibly.

The third problem is that students lack rational thinking about the integration and development potential of their job position. For a long time, the roles were mainly assigned by the teacher. Most students didn't know whether they were suitable for those roles and had no interest in the passive roles, so they cannot truly integrate into the business simulation operation of the economic activities. That was not only difficult to adapt to the requirements of the roles, but also difficult to finish the role play work, which resulted in puzzle and no confidence about the future career choice. At bottom, the distribution of jobs didn't match the actual situation of students, so that the experimental class couldn't achieve the desired purpose.

\section{Reform ideas of ECREST}

Through thinking about the problems in ECREST, we have summed up as a chain: first, those roles by students are not matched with the job requirements and the students are not interested in the assigned posts; thus, the rules of the experiment course are not clear and the low participation results in the class polarization of the course performance; at last, the course will not be able to guide the career planning.

Obviously, it is a key problem of ECREST that students didn't work well. So how to help students find suitable roles that interest them is critical to the course reform. Modern psychology believes that interest can lead to a motivation, the motivation can promote a person to accomplish a task, and a strong motivation can also keep people on one thing and eventually achieve success. Therefore, our solutions are the way to let students decide their own roles and turn the passive teacher assignment system into the active selection system of students. The students' classroom performance shows that most of the students agree with the way of "choosing" and have a strong motivation to choose the roles by themselves. However, because that they hadn't be scientifically guided in the selection of roles, many students hadn't rational analysis of their personality, so that they have not yet formed a rational career planning. 
Through the communication with the students, the teacher found that most of the students with clear goals selected those roles from their own personality. Some students didn't know mismatch between their own personality and role responsibilities, it was easy to bring about the state of "choosing blindness".

\section{Innovation of ECREST}

The innovation of this course is to draw on John Holland's theory of personality type and make it a tool to guide students' rational understanding of their own personality, and help students to change passivity into the initiative and blindness to reason in the role selection and career choice of ECREST.

John Holland was a professor of psychology at the Johns Hopkins University in the United States, a famous American Career Guide expert. He was the creator of the career development model, Holland Occupational Themes, otherwise known as The Holland Codes. He later developed and changed his six types of as "Realistic (Doers), Investigative (Thinkers), Artistic (Creators), Social (Helpers), Enterprising (Persuaders), and Conventional (Organizers).”

The core of Holland's theory is to combine personality characteristics and occupation orientation organically. Since the second half of 2017, we first cooperated with psychological experts to test the type of occupational character of the students. Then, guided by Holland's ideas and based on the professional characteristics of the manager role of the real estate company, we initially set up a corresponding matching relationship and drew it into a table to help students choose their own professional role, as shown in Table 1.

Table 1 Occupational Character Orientation of Manager Role

\begin{tabular}{|c|l|l|}
\hline No. & \multicolumn{1}{|c|}{ Manager Role } & \multicolumn{1}{c|}{ Occupational Character Orientation } \\
\hline 1 & CEO & Enterprising type, Social type \\
\hline 2 & Chief Financial Officer & Conventional type, Investigative type \\
\hline 3 & Design Director & Realistic type, Artistic type \\
\hline 4 & Engineering Director & Realistic type, Conventional type \\
\hline 5 & Sales Director & Enterprising type, Social type \\
\hline 6 & Cost Director & Conventional type, Investigative type \\
\hline
\end{tabular}

\section{The Actual Effect of ECREST Reform}

After the guidance of the occupational character in the ECREST, it is obvious that the attendance rate of the students is greatly improved. The whole class presents the state of the orderly operation state of each company by the student team. The concentration of the class is also greatly enhanced. When they discussed the problem of the planning of the business, every student can make suggestions from his own point of view of manager role. Some suggestions are well-founded and worthwhile to analyze the real situation of real estate in China.

In order to accurately characterize the results of course reform on classroom, we conducted a questionnaire survey on 69 students in 2015 class. It can be seen that $68 \%$ of the students choose those roles by their own interests, while more than $80 \%$ of the 
students take into account the factors of career development, and $43 \%$ of the students connect their own personality with their adaptable occupation when choosing those roles. It is found that most of the students are interested in their chosen roles in the process of ECREST, but $17 \%$ of the students are still not interested in the experiment course.

To sum up, role interest by personality characteristics has an important value in the establishment of students' career plan, and there is a clear and positive correlation with occupation orientation and job competence. It is an important way to improve the quality of education through a variety of means to improve the students' role interest.

After the questionnaire, we interviewed some of the students. Many students said, "We are going to step into the society and go to work. The ECREST not only lets us try the future occupation life, but also makes us find the shortcoming of our ability and knowledge, and sees the direction that we should work hard in the future." Some students reflected that "the ECREST simulates the division and cooperation of different manager roles in the real estate company operation, and makes a glimpse of the professional ecology of the modern real estate industry". When we discussed Holland's personality type theory to help select roles, some students reflected, "We selected occupation mainly by considering the amount of income, and after the psychological test of the course, we have a more sober understanding of our professional interests, and have a more reasonable expectation of our career potential."'We will make greater efforts to develop ourselves and realize our professional dreams."

\section{Conclusion}

The ECREST is an important link in the change of the students to the professional roles, and is an important embodiment of the university education quality. We will strive to build this course to enable students to discover and create a more mature and better professional role in a more realistic market environment.

\section{References}

[1] Wanli WANG, Shuang LI. Guidance Course of Real Estate Enterprise Management Sand Table [M]. Shanghai: Shanghai University of Finance and Economics press, 2015. 56-67.

[2] Lianlong LIU, Dan XU, Shan HE. Research on College Students' Professional Interest and the Countermeasures [J]. Research on Higher Engineering Education, 2009 (2) :116-120. 